\title{
"See one, do one, teach one": It is still possible in cardiothoracic surgical education
}

\author{
Jared P. Beller, MD, and Irving L. Kron, MD
}

\author{
From the Division of Thoracic and Cardiovascular Surgery, University of Virginia, Charlottesville, Va. \\ Disclosures: Authors have nothing to disclose with regard to commercial support. \\ Received for publication April 9, 2018; accepted for publication April 10, 2018; available ahead of print May 8, \\ 2018 \\ Address for reprints: Irving L. Kron, MD, Division of Thoracic and Cardiovascular Surgery, Department of \\ Surgery, University of Virginia, PO Box 800679, Charlottesville, VA 22908 (E-mail: ILK@hscmail.mcc. \\ virginia.edu). \\ J Thorac Cardiovasc Surg 2018;156:716-7 \\ $0022-5223 / \$ 36.00$ \\ Copyright $(2) 2018$ by The American Association for Thoracic Surgery \\ https://doi.org/10.1016/j.jtcvs.2018.04.042
}

Recent editions of the Journal have highlighted various cardiothoracic training paradigms throughout the world. This month, Shi and colleagues ${ }^{1}$ provide an in-depth description of the current system in Australia and New Zealand. Shi and colleagues ${ }^{1}$ begin by reviewing the contributions of Australian and New Zealand surgeons to cardiothoracic surgery, and they then focus their discussion on the specifics of achieving board certification as a Fellow of the Royal Australasian College of Surgeons (RACS) in Cardiothoracic Surgery. Notable is the relatively prolonged training course, which at a minimum requires 9 to 10 years. This is of particular interest in the current landscape, in which more North American institutions have embraced an integrated training pathway and thereby reduced postgraduate training to as little as 6 years. Equally important, and perhaps directly related to the length of training, is the systematic assurance of trainee independence.

Graduated independence is the goal of any surgical training program, as embodied by the aphorism, "See one, do one, teach one." The path to proficiency in complex operations is never that simple; however, as the RACS shows us, intelligently designed systems can facilitate both education and autonomy.

On the surface, case requirements seem similar to those of the Accreditation Council for Graduate Medical Education (ACGME), with specified numbers of component and major index cases. Where they differ, however, is by beginning to track cases at the level of first assistant and progressing through independent surgeon, where the senior surgeon is required to be unscrubbed. The architects of this system are to be commended on their creation of a structure that quantifies and values participation at every stage of training.

The RACS uses directly observed, skill-specific assessments in place of traditional year-based qualifications. These regular, informal assessments certify trainees as

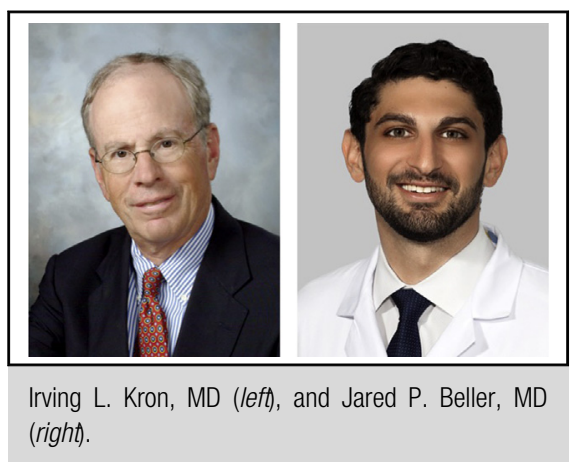

Central Message

Cardiothoracic education in Australia and New Zealand focuses on graded autonomy while producing competent surgeons ready for independent practice.

See Article page 718

competent to perform procedural skills independently. In addition, board certification is not rigidly tied to a prespecified length of time.

As Shi and colleagues ${ }^{1}$ openly recognize, the incorporation of wire-based skills and integration with cardiology trainees is an area in need of ongoing development. This resonates with many of our experiences, because the dynamic skill set required of the modern cardiac surgeon is a moving target. We as educators need to ensure competency in these less traditional areas of surgical education. The RACS brings trainees together for clinical simulation, team exercises, and skills laboratories on at least a semiannual basis. These frequent trainee-focused events, removed from clinical responsibility, appear similar to the recently studied program in the United Kingdom. ${ }^{2}$ Collaborative, simulation-based efforts should be incorporated into other national systems to foster community and to ensure consistency among training centers.

By any standard, the RACS cardiothoracic education achieves excellence, with graduating surgeons ready for independent practice. We have experienced this firsthand with a number of Australian and New Zealand trainees who have excelled during their time in our department. Although formal training is the foundation, thoracic surgical education does not end when residency is completed. There needs to be more emphasis on rigorous surgical mentoring at the beginning of independent practice. 


\section{References}

1. Shi WY, Oldfield Z, Tam R, Cochrane AD, Smith JA. Cardiothoracic Surgery training in Australia and New Zealand. J Thorac Cardiovasc Surg. 2018;156: 718-25.
2. Moorjani N, Lewis ME, Shah RD, Barnard S, Graham TR, Rathinam S Implementation of a novel portfolio of structured, curriculum-aligned, simulation-based, cardiothoracic surgery training courses: evolving the delivery of surgical education. J Thorac Cardiovasc Surg. 2017;154:2009-16. 